\title{
Patogenitas Isolat Jamur Entomopatogenik Metarhizium anisopliae terhadap Lalat Rumah Musca domestica L. (Diptera: Muscidae)
}

\author{
Noni Yunizar ${ }^{1}$, Rahmawati ${ }^{1}$, Kustiati ${ }^{1}{ }^{*}$ \\ ${ }^{1}$ Program Studi Biologi,Fakultas MIPA, Universitas Tanjungpura, Jl. Prof. Dr. H.Hadari Nawawi, Pontianak \\ *Email korespondensi: kustiati@fmipa.untan.ac.id
}

\begin{abstract}
Metarhizium anisopliae is one of the entomopathogenic fungi that can be used to control house fly, Musca domestica. The aim of this study is to determine the effectiveness of fungus Metarhizium anisopliae in killing house flies. This study used a Completely Randomized Design (CRD) with 5 treatment concentration of Metarhizium anisopliae fungal suspension concentration of $1 \times 10^{6}$ conidia/mL, $3 \times 10^{6}$ conidia $/ \mathrm{mL}, 5 \times 10^{6}$ conidia/mL, $7 \times 10^{6}$ conidia/mL, $9 \times 10^{6}$ conidia/mL with each repetition three times. The fungal pathogenicity was determined by the lethal time of $50 \%$ flies $\left(\mathrm{LT}_{50}\right)$ for each concentration using Probit analysis. The result of this study showed that the time required to killing $50 \%$ of flies in consecutive consentrations was 7 days with concentrations ranging from $3 \times 10^{6}$ conidia $/ \mathrm{mL}$ until $5 \times 10^{6}$ conidia/mL. In conclusion, the fungus Metarhizium anisopliae is effectively deadly pest house flies Musca domestica.
\end{abstract}

Keywords: Metarhizium anisopliae, Musca domestica, entomopathogen, biological control.

\section{PENDAHULUAN}

Musca domestica atau lalat rumah merupakan salah satu serangga yang banyak terdapat di seluruh dunia. Sekitar 95\% dari berbagai spesies lalat yang sering dijumpai di sekitar rumah dan kandang peternakan adalah lalat spesies ini. Lalat rumah dianggap sebagai serangga pengganggu di bidang kesehatan, karena merupakan vektor mekanis beberapa penyakit pada manusia dan hewan yang disebabkan oleh virus, bakteri, protozoa, dan cacing. Selain berperan dalam penularan dan penyebaran patogen, lalat rumah juga dapat menimbulkan ketidaknyamanan dari kebersihan (Lestari et al., 2005).

Hingga saat ini, salah satu cara yang paling sering dilakukan untuk mengendalikan lalat rumah adalah dengan menggunakan insektisida. Namun, penggunaan insektisida tersebut telah memimbulkan resistensi pada lalat rumah. Selain secara kimiawi, pengendalian lalat rumah dapat dilakukan secara biologi dengan menggunakan agen biologi, seperti jamur mikroskopis. Beberapa penelitian telah berhasil mengisolasi berbagai jamur entomopatogen yang dapat digunakan untuk mengendalikan hama seperti Beauveria bassiana, Duddingtonia flagrans, dan Metarhizium sp. Jamur Metarhizium sp. tergolong paling umum digunakan karena efektif dalam berbagai tingkat perkembangan serangga mulai dari telur, larva, pupa dan imago. Hal ini karena jamur M. anisopliae dilaporkan bersifat toksik terhadap serangga seperti nimfa Sogatella frucifera, (Herlinda et al., 2008) dan telur Blissus antillus (Hemiptera: Lygalidae) (Samuels et al., 2002), serta larva Phragmatoecia castanae (Prasasya, 2008).

Penggunaan agen hayati jamur entomopatogen sebagai pestisida biologi diharapkan dapat menjadi solusi untuk pengendalian serangga tanpa menimbulkan masalah lingkungan. Salah satu jamur entomopatogen yan potensial digunakan sebagai agen hayati adalah M.anisopliae. Hasil penelitian yang telah dilakukan oleh Amiruddin (2012) menunjukkan bahwa persentase kematian tertinggi larva lalat Musca domestica dengan jamur M.anisopliae pada konsentrasi 5,1 x $10^{10}$ konidia/mL mencapai 93,33\%. Penelitian efek jamur patogenik M.anisopliae terhadap imago lalat rumah belum banyak dilaporkan. Oleh karena itu, dalam penelitian ini akan dilakukan aplikasi isolat jamur M.anisopliae terhadap imago lalat Musca domestica.

\section{BAHAN DAN METODE}

\section{Waktu dan Tempat Penelitian}

Penelitian dilakukan pada bulan September 2017 hingga Februari 2018 di Laboratorium Mikrobiologi dan Laboratorium Zoologi, Fakultas Matematika dan Ilmu Pengetahuan Alam, Universitas Tanjungpura, Pontianak.

\section{Cara Kerja}

Sterilisasi alat

Alat-alat yang digunakan dalam penelitian, seperti cawan petri, gelas ukur, dan tabung reaksi dicuci 
menggunakan deterjen lalu dibilas dengan air hingga bersih dan dibiarkan kering. Peralatan yang telah kering kemudian dibungkus dengan kertas merang dan disterilisasi menggunakan autoklaf pada suhu $121^{\circ} \mathrm{C}$ dengan tekanan dua atm selama 15 menit.

\section{Pembuatan Medium PDA (Patato Dextrose Agar)} Sebanyak 19,5 gram serbuk medium PDA dimasukkan ke dalam gelas beker, kemudian ditambahkan aquades hingga mencapai $500 \mathrm{ml}$ selanjutnya dipanaskan hingga mendidih. Medium PDA yang telah mendidih ditambahkan dengan $1 \mathrm{ml}$ larutan Ciprofloxacin (250mg dalam $100 \mathrm{ml}$ akuades) yang berfungsi sebagai antibakteri, kemudian dihomogenkan. Medium PDA tersebut disterilisasi menggunakan autoklaf pada suhu $121^{\circ} \mathrm{C}$ dengan tekanan $2 \mathrm{~atm}$ selama 15 menit. Medium PDA yang telah steril dituang secara aseptis sebanyak $\pm 15 \mathrm{ml}$ ke dalam cawan petri. Cawan petri yang berisi medium PDA ditutup dan dibiarkan selama 15 menit hingga medium PDA memadat.

\section{Pembiakan Jamur Metarhizium anisopliae}

Isolat jamur Metarhizium anisopliae yang diperoleh dari BPTP (Badan Proteksi Tanaman Perkebunan) hasil isolasi dari Orytes rhinoceros, ditumbuhkan dalam medium PDA pada suhu $26^{\circ} \mathrm{C}$ selama 14 hari menggunakan metode tusuk. Pada awal pertumbuhan koloni jamur ini berwarna putih, setelah 14 hari mulai tumbuh banyak dan berubah menjadi warna hijau gelap saat konidia matang yang menandakan bahwa jamur tersebut siap untuk diujikan terhadap lalat Musca domestica

\section{Pemeliharaan Lalat Musca domestica}

Lalat rumah yang digunakan dalam penelitian ini berasal dari tempat pembuangan sampah sementara pasar, tempat pembuangan akhir dan peternakan yang berada di Pontianak. Sampel lalat rumah dari populasi lapangan dipelihara dalam kotak kasa berukuran $30 \mathrm{~cm}$ x $30 \mathrm{~cm}$ x $30 \mathrm{~cm}$ di laboratorium pada suhu ruangan. Lalat rumah yang digunakan sebagai hewan uji merupakan generasi pertama hasil perkembangbiakan di laboratorium. Pakan imago terdiri atas campuran susu bubuk 50 gram, ragi 1 gram dan gula 50 gram diberikan secara berlebihan dalam wadah terpisah dengan air untuk minum. Setiap populasi disediakan ovitrap dengan menggunakan tisu yang sudah dibasahi susu 5\% sebagai tempat perletakkan telur bagi lalat betina. Setelah 24 jam, ovitrap yang telah mengandung larva instar pertama dipindahkan ke medium larva yang terdiri atas campuran dedak dan pakan ayam dengan perbandingan 2:1 dan dicampur dengan 3 bagian air, hingga menjadi pupa. Pupa dipelihara dalam kurungan terpisah hingga muncul menjadi imago lalat rumah dan lalat yang sudah berumur 5-6 hari selanjutnya digunakan sebagai lalat percobaan (Kustiati et al., 2016).

\section{Pembuatan Suspensi dan Penghitungan Spora} Jamur Metarhizium anisopliae

Pembuatan suspensi konidia dilakukan dengan cara mengambil koloni jamur dari biakan ke dalam tabung reaksi yang telah berisi $30 \mathrm{ml}$ aquades steril, selanjutnya divorteks sampai seluruh jamur menjadi homogen. Suspensi yang telah terbentuk digunakan sebagai stok dan dihitung jumlah sporanya menggunakan haemositometer dengan mikroskop. Perhitungan spora jamur Metarhizium anisopliae dengan menggunakan rumus sebagai berikut:

$$
C=\frac{t}{n \times 0,25} \times 10^{6}
$$

$\mathbf{C}$ adalah kerapatan spora per $\mathrm{ml}$ larutan, $\mathbf{t}$ adalah jumlah total spora dalam kotak sampel yang diamati, n adalah jumlah kotak sampel (5 kotak besar x 16 kotak kecil), dan $\mathbf{0 , 2 5}$ adalah faktor koreksi penggunaan kotak sampel skala kecil haemocytometer.

\section{Uji Hayati}

Sebelum dilakukan uji hayati, terlebih dahulu dipersiapkan lima larutan perlakuan konsentrasi suspensi jamur anggota spesies M.anisopliae, yaitu $1 \times 10^{6}, \quad 3 \times 10^{6}, \quad 5 \times 10^{6}, \quad 7 \times 10^{6}, \quad 9 \times 10^{6}$ konidia/ml akuades dalam tabung reaksi dengan menggunakan rumus sebagai berikut:

\section{V1.N1 = V2.N2}

keterangan:

V1: Volume awal suspensi jamur M.anisopliae $(\mathrm{ml})$

N1: Konsentrasi awal suspensi jamur M.anisopliae (spora/ml)

V2: Volume pengeceran media uji $(\mathrm{ml})$, total volume $10(\mathrm{ml})$

N2: Konsentrasi pengeceran jamur Metarhizium anisopliae $(\mathrm{spora} / \mathrm{ml})$

Lima tabung reaksi yang masing-masing telah diisi dengan $9 \mathrm{ml}, 7 \mathrm{ml}, 5 \mathrm{ml}, 3 \mathrm{ml}$ dan $1 \mathrm{ml}$ aquades dimasukkan suspensi jamur anggota spesies Metarhizium anisopliae berturut-turut 1 $\mathrm{ml}, 3 \mathrm{ml}, 5 \mathrm{ml}, 7 \mathrm{ml}$, dan $9 \mathrm{ml}$. Penginfeksian lalat uji diberikan sebagai minum. Sebanyak $3 \mathrm{ml}$ dari tiap-tiap perlakuan disemprotkan pada cawan kecil dan diletakan dalam toples perlakuan. Selanjutnya, ke dalam toples perlakuan, yang sudah berisi larutan perlakuan dan gula pakan 
serta ditutup dengan menggunakan potongan stocking berbahan kain katun, dimasukkan 10 individu lalat uji. Toples berisi lalat dengan hanya diberi akuades digunakan sebagai kontrol. Pengamatan dilakukan setiap 24 jam sekali setelah perlakuan selama 14 hari. Jumlah lalat yang mati dicatat, kemudian diinkubasi dan diisolasi jamur yang tumbuh pada tubuh lalat untuk dilakukan pengamatan secara mikroskopis.

\section{Analisis Data}

Data berupa jumlah kematian lalat setiap harinya dianalisis secara probit dengan bantuan software Microsoft Excel 2010 untuk menetukan nilai waktu kematian 50\% $\left(\mathrm{LT}_{50}\right)$ untuk tiap - tiap konsentrasi perlakuan (Finney, 1971 dalam Amiruddin et al., 2012). Setelah nilai waktu kematian $50 \%$ ( $\mathrm{LT}_{50}$ ) diperoleh kemudian data dianalisis secara deskriptif.

\section{HASIL DAN PEMBAHASAN}

Hasil

Karakter Morfologis Isolat Jamur anggota spesies Metarhizium anisopliae

Hasil pengamatan secara makroskopis karakteristik koloni jamur anggota spesies $M$. anisopliae strain Orytes rhinoceros yang akan digunakan untuk menginfeksi lalat tampak berwarna hijau gelap. Sedangkan secara mikroskopis, jamur memiliki miselium bersekat, dan konidiofor bercabang yang dipenuhi spora atau disebut konidia, yang berbentuk bulat lonjong. Isolat koloni jamur anggota spesies $M$. anisopliae yang tumbuh pada lalat rumah setelah perlakuan memiliki karakter yang sama dengan koloni jamur anggota spesies $M$. anisopliae strain Orytes rhinoceros (Gambar 1).

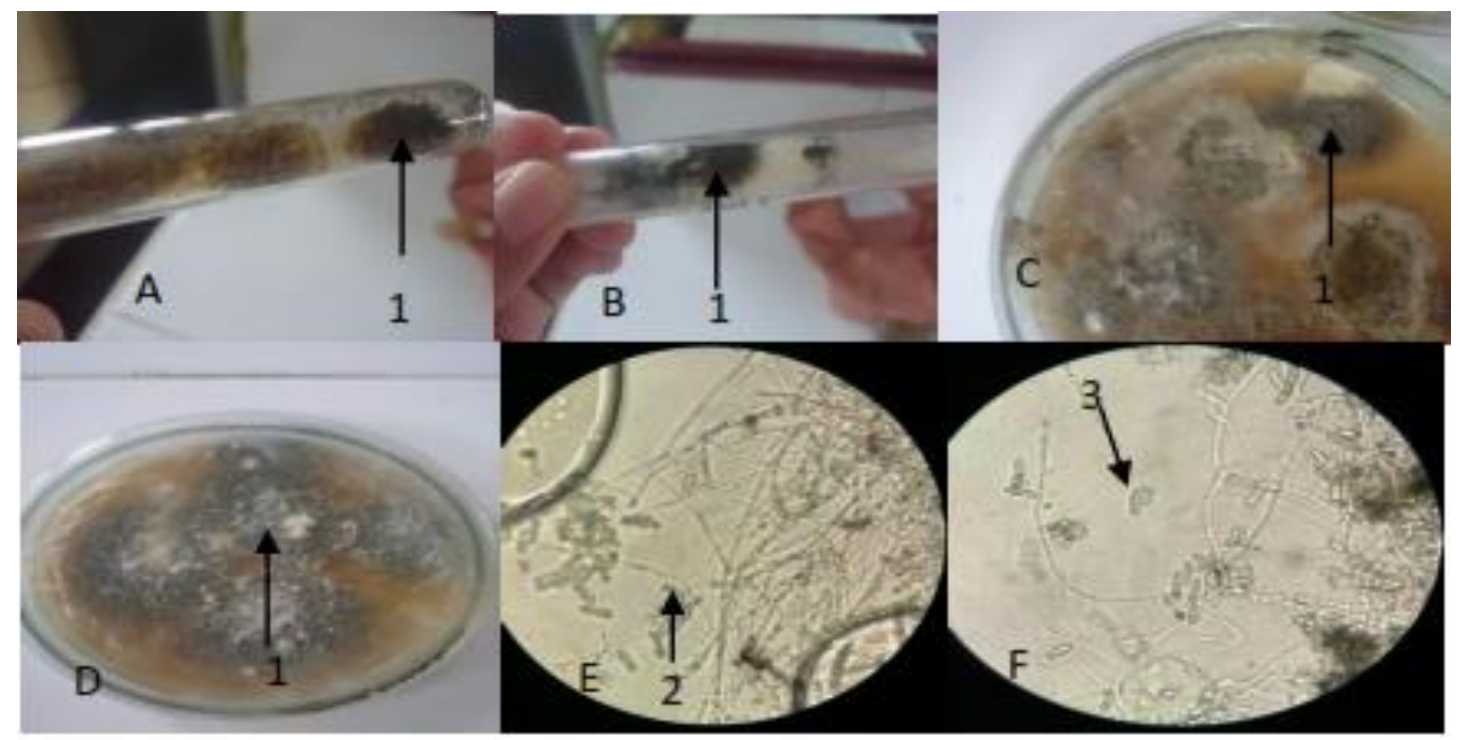

Gambar 1. Morfologi jamur anggota spesies Metarhizium anisopliae secara makroskopis. A. Isolat jamur anggota spesies M. anisopliae berasal dari $O$. rhinoceros berumur 28 hari, B. Isolat jamur anggota spesies $M$. anisopliae yang tumbuh dari $M$. domestica setelah terinfeksi M.anisopliae berasal dari $O$. rhinoceros berumur 21 hari,C. Isolat jamur anggota spesies $M$. anisopliae berasal dari $O$. rhinoceros berumur 14 hari, D. Isolat jamur anggota spesies $M$. anisopliae yang tumbuh dari $M$. domestica setelah terinfeksi berumur 14 hari, E. \& F. Pengamatan secara mikroskopis (perbesaran 400x), 1. Koloni jamur anggota spesies M. anisopliae, 2. Miselium jamur anggota spesies M. anisopliae,3.Konidia jamur anggota spesies M. anisopliae.

Siklus hidup lalat Musca domestica

Hasil pengamatan siklus hidup lalat Musca domestica dimulai dari periode telur hingga menjadi imago dari masing-masing populasi memiliki perbedaan waktu untuk tumbuh. Lalat rumah yang dikoleksi dari TPA menyelesaikan perkembangannya dari telur menjadi imago lebih lama dibandingkan lalat rumah yang dikoleksi dari TPS dan peternakan ayam (Tabel.1). 
Protobiont (2018) Vol. 7 (3) : 77 -82

Tabel 1. Siklus hidup lalat Musca domestica

\begin{tabular}{|c|c|c|c|c|c|}
\hline \multirow{2}{*}{$\begin{array}{c}\text { Asal } \\
\text { Populasi } \\
\text { Lalat Rumah }\end{array}$} & \multirow{2}{*}{$\begin{array}{l}\text { Telur } \\
\text { (jam) }\end{array}$} & \multicolumn{3}{|c|}{ Larva (jam) } & \multirow[t]{2}{*}{ Pupa (hari) } \\
\hline & & Instar 1 & Instar 2 & Instar 3 & \\
\hline TPS Pasar & $7-8$ & $23-25$ & $47-49$ & $95-97$ & $6-8$ \\
\hline TPA & $6-7$ & $23-25$ & $71-73$ & $119-121$ & $6-8$ \\
\hline Perternakan Ayam & $6-7$ & $23-25$ & $47-49$ & $95-97$ & $5-7$ \\
\hline
\end{tabular}

Perbedaan waktu perkembangan lalat rumah disebabkan oleh suhu lingkungan. Pemeliharan lalat rumah yang diambil dari TPS pada tanggal 10-26 September 2017, dengan kisaran suhu ruang $27-29^{\circ} \mathrm{C}$. Pemeliharaan lalat rumah yang diambil dari tempat pembuangan sampah akhir pada tanggal 3-18 November 2017 dengan kisaran suhu $25-29^{\circ} \mathrm{C}$. Pemeliharaan lalat rumah yang diambil dari peternakan ayam dilaksanakan pada tanggal 15-30 Desember 2017 dengan kisaran $27-30^{\circ} \mathrm{C}$. Pengukuran suhu ruang di Laboratorium Zoologi (Gambar 2).

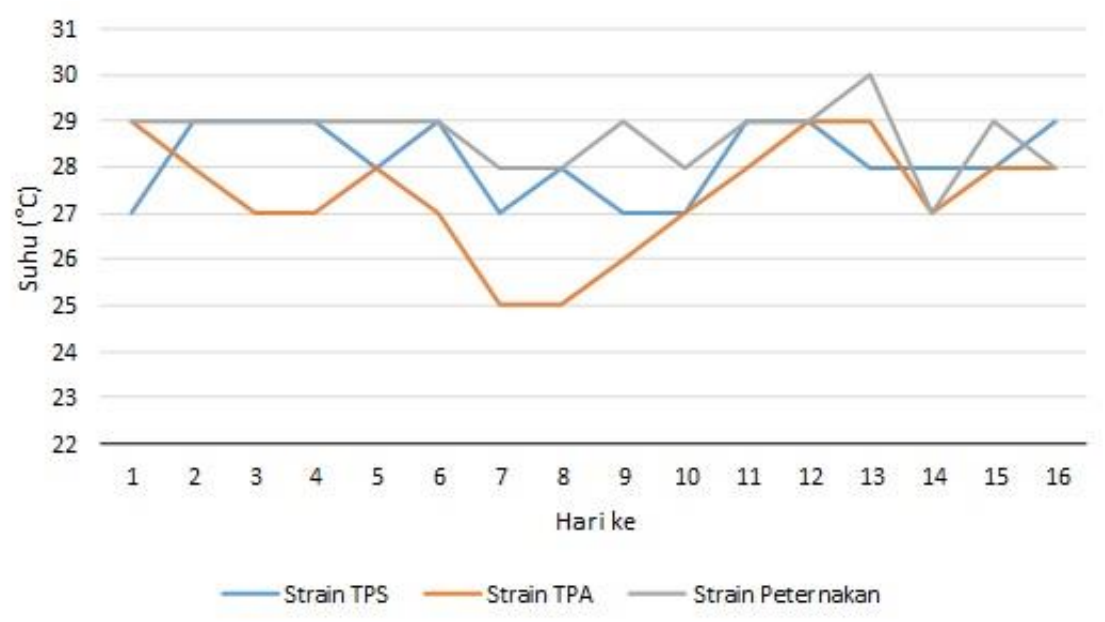

Gambar 2. Suhu harian pemeliharaan lalat M.domestica

Tabel 2. Uji Hayati Metarhizium anisopliae terhadap lalat Musca domestica

\begin{tabular}{|c|c|c|c|c|c|c|}
\hline \multirow{3}{*}{$\begin{array}{l}\text { Konsentrasi } \\
\text { (konidia/ml) }\end{array}$} & \multicolumn{6}{|c|}{ Strain Lalat Rumah } \\
\hline & \multicolumn{2}{|c|}{ TPS Pasar } & \multicolumn{2}{|c|}{ TPA } & \multicolumn{2}{|c|}{ Peternakan Ayam } \\
\hline & $\begin{array}{c}\mathrm{LT}_{50} \\
\text { (FI 95\%) }\end{array}$ & Slope \pm SD & $\begin{array}{c}\mathrm{LT}_{50} \\
\text { (FI 95\%) }\end{array}$ & Slope \pm SD & $\begin{array}{c}\mathrm{LT}_{50} \\
\text { (FI 95\%) }\end{array}$ & Slope \pm SD \\
\hline $1 \times 10^{6}$ & $\begin{array}{c}8,68 \\
(7,77-9,70)\end{array}$ & $5,542 \pm 0,18$ & $\begin{array}{c}7,99 \\
(6,32-10,11)\end{array}$ & $2,196 \pm 0,45$ & $\begin{array}{c}9.93 \\
(7,42-13,30)\end{array}$ & $1,753 \pm 0,57$ \\
\hline $3 \times 10^{6}$ & $\begin{array}{c}7,45 \\
(6,05-9,18)\end{array}$ & $2,520 \pm 0,39$ & $\begin{array}{c}9,91 \\
(7,73-12,70)\end{array}$ & $2,097 \pm 2,95$ & $\begin{array}{c}8,30 \\
(6,40-10,77)\end{array}$ & $1,971 \pm 0,50$ \\
\hline $5 \times 10^{6}$ & $\begin{array}{c}8,02 \\
(7,23-8,86)\end{array}$ & $6,462 \pm 0,15$ & $\begin{array}{c}7,14 \\
(5,63-9,05)\end{array}$ & $2,166 \pm 0,46$ & $\begin{array}{c}7,74 \\
(5,99-9,98)\end{array}$ & $2,005 \pm 0,49$ \\
\hline $7 \times 10^{6}$ & $\begin{array}{c}7,77 \\
(6,96-8,69)\end{array}$ & $5,621 \pm 0,18$ & $\begin{array}{c}7,12 \\
(5,43-9,34)\end{array}$ & $1,869 \pm 0,53$ & $\begin{array}{c}6,99 \\
(5,07-9,65)\end{array}$ & $1,551 \pm 0,65$ \\
\hline $9 \times 10^{6}$ & $\begin{array}{r}5,59 \\
(4,75-6,59)\end{array}$ & $3,440 \pm 0,29$ & $\begin{array}{c}9,63 \\
(7,17-12,92)\end{array}$ & $1,731 \pm 0,58$ & $\begin{array}{c}7,07 \\
(5,75-8,70)\end{array}$ & $2,554 \pm 0,39$ \\
\hline
\end{tabular}


Uji Hayati Jamur M. anisopliae terhadap Lalat Musca domestica

Hasil pengamatan uji hayati jamur anggota spesies Metarhizium anisopliae terhadap lalat rumah M.domestica, memiliki nilai $\mathrm{LT}_{50}$ yang berbeda dari masing-masing populasi lalat rumah (Tabel 2).

\section{Pembahasan}

Karakteristik koloni jamur Metarhizium anisopliae yang diisolasi dari Orytes rhinoceros sebagai koloni awal dan jamur $M$. anisopliae setelah diinfeksikan pada lalat Musca domestica memiliki ciri karakter miselium dan konidia yang sama, hal ini menunjukkan bahwa isolat jamur $M$. anisopliae yang menginfeksi lalat rumah $M$. domestica adalah berasal dari isolat jamur spesies $M$. anisopliae strain $O$. rhinoceros. Pertumbuhan koloni jamur anggota spesies $M$. anisopliae berwarna putih di awal pertumbuhan. Warna koloni menjadi hijau tua menandakan bahwa konidia sudah matang ketika berumur 7 hari.

Hasil pengamatan uji hayati dari jamur M.anisopliae efektif terhadap imago lalat $M$. domestica karena menyebabkan mortalitas sebesar 50\% dalam waktu 7 hari dari hari penginfeksian jamur entomopatogen dengan konsetrasi yaitu $3 \times 10^{6} \mathrm{konidia} / \mathrm{ml}-5 \times 10^{6} \mathrm{konidia} / \mathrm{ml}$. Amiruddin (2012) melakukan uji hayati jamur anggota spesies M. anisopliae terhadap lalat M. domestica pada fase larva dengan konsentrasi $8,317 \times 10^{6}$ konidia/ml dapat menyebabkan mortalitas lalat sebesar $50 \%$.

Waktu efektif yang diperlukan untuk mematikan hewan uji strain TPS sebanyak 50\% dengan konsentrasi $3 \times 10^{6}$ konidia/ml dan dengan slope 2,520 yaitu 7,45 hari. Selanjutnya waktu efektif yang diperlukan untuk mematikan hewan uji populasi TPA sebanyak 50\% dengan konsentrasi $5 \times 10^{6}$ konidia/mL dan slope 2,166 yaitu 7,14 hari. kemudian waktu efektif yang diperlukan untuk mematikan hewan uji populasi peternakan sebanyak $50 \%$ dengan konsentrasi $5 \times 10^{6}$ konidia/ml dan slope 2,005 yaitu 7,74 hari.

Data yang diperoleh menunjukkan bahwa jamur M.anisopliae efektif bersifat patogen terhadap hewan uji populasi TPS dibandingkan hewan uji populasi TPA dan populasi peternakan, dilihat dari konsentrasi rendah mampu mematikan hewan uji dalam waktu 7 hari, sedangkan dengan konsentrasi yang sama hewan uji populasi TPA memiliki waktu lebih cepat dibandingkan hewan uji populasi peternakan. Hal ini dipengaruhi oleh perbedaan waktu perkembangan hewan uji yang disebabkan oleh suhu lingkungan. Perkembangan siklus hidup lalat rumah dimulai dari fase telur hewan uji populasi TPS lebih lama karena suhu ruang rendah yaitu $27^{\circ} \mathrm{C}$, hewan uji populasi TPA fase menjadi larva lebih lama arena suhu ruang $25-28^{\circ} \mathrm{C}$, fase menjadi pupa lebih cepat terjadi pada hewan uji populasi TPS dengan suhu ruang $28^{\circ} \mathrm{C}$, kemudian fase dari pupa menjadi imago lebih cepat terjadi pada hewan uji populasi TPS dengan suhu $28-29^{\circ} \mathrm{C}$. Menurut Chapman JW \& D Goulson (2000) semakain tinggi suhu semakin cepat perubahan larva instar ketiga menjadi pupa.

Jamur $M$. anisopliae mampu menyebabkan kelumpuhan dan kematian pada serangga antara tiga dan empat belas hari setelah infeksi, tergantung dari jenis dan ukuran (Widiyanti \& Muyadihardja, 2004). Hewan serangga Plutella xylostella dengan konsentrasi lebih rendah dari konsentrasi hewan uji populasi TPS yaitu $1 \times 10^{6}$ konidia/ml dengan nilai $\mathrm{LT}_{50}$ yaitu 2,24 hari (Nunilahwati et al., 2013), konsentrasi tinggi yaitu $10^{7}$ konidia/ml terhadap serangga Brontispa longissima dengan nilai $\mathrm{LT}_{50}$ 25,67 jam (Irwan, 2016) dan Conopomorpha cramerella dengan nilai LT $_{50}$ 3,4 hari (Trizelia, 2013). Konsentrasi serangga penyerbuk Trigona sp mematikan 50\% pada konsentrasi $10^{10} \mathrm{konidia} / \mathrm{ml}$ (Yanti, 2013), sedangkan pada fase telur serangga Spodoptera litura mematikan sekitar 18,67-75,38\% pda konsentrasi $10^{8} \mathrm{konidia} / \mathrm{ml}$ (Trizelia, 2011). M. anisopliae mampu efektif mematikan serangga Nephotettix virescent Distant sebesar 87,75\% (Rosmini dan Sri Anjar Lasmini, 2010).

Jamur M. anisopliae memiliki aktivitas larvisidal karena menghasilkan cyclopeptida, destruxin dan desmethyldestrusin. Jamur anggota spesies $M$. anisopliae menghasilkan endotoksin yang mematikan yaitu destruxins. Senyawa destruxin $\mathrm{A}, \mathrm{B}, \mathrm{C}, \mathrm{D}, \mathrm{E}$ dan demethyl destruxintin dipertimbangkan sebagai bahan insektisida generasi baru. Efek destruxin berpengaruh pada organel target yaitu mitokondria, retikulum endoplasma dan membran nukleus yang menyebabkan parasitis sel dan kelainan fungsi terhadap lambung tengah, tubulus malphigi, hemocit dan jaringan otot (Widiyanti \& Muyadihardja, 2004). Dari penelitan yang telah dilakukan dapat disimpulkan bahwa jamur $M$. anisopliae efektif sebagai jamur entomopatogen terhadap imago lalat $M$. domestica, hal ini ditunjukan dari konsentrasi rendah dapat mematikan lalat uji sebesar $50 \%\left(\mathrm{LT}_{50}\right)$ dan pertumbuhan jamur $M$. anisopliae pada lalat rumah yang sudah mati terinfeksi jamur anggota spesies $M$. anisopliae. Nilai $\mathrm{LT}_{50}$ pada populasi 
lalat rumah pasar dahlia yaitu 7,45 hari dengan konsentrasi $3 \times 10^{6} \mathrm{konidia} / \mathrm{ml}$. Populasi lalat rumah TPA Rasau $\mathrm{LT}_{50}$ sebesar 7,14 hari dengan konsentrasi $5 \times 10^{6}$ konidia/ml dan populasi lalat rumah perternakan ayam $\mathrm{LT}_{50}$ sebesar 7,74 hari dengan konsentrasi $5 \times 10^{6} \mathrm{konidia} / \mathrm{ml}$.

\section{DAFTAR PUSTAKA}

Amiruddin M, Umrah \& Alwi M, 2012, 'Keefektifan Metarhizium anisopliae sebagai Agen Pengendali hayati terhadap Larva Lalat Musca domestica L', Biocelebes, hlm. 48-55, ISSN: 1978-6417.

Chapman JW \& D Goulson, 'Environmental Versus Genetic Influence on Fluctuating Asymmetry in The House Fly, Musca domestica' Biol, J. Linn, 2000; 70,403 - 413, diakses tanggal 26 Mei 2018, http://doi.org/10.1111/j.10958312.2000.tbol231.x.

Herlinda, S., Hartono. Irsan, C. 2008. Efikasi Bioinsektisida Formulasi Cair Berbahan Aktif Beauveria bassiana (Bals.) Vuill. dan Metarhizium Sp. pada Wereng Punggung Putih (Sogatella furcifera Horv. Seminar Nasional dan Kongres PATPI 2008, Palembang.

Irwan, 2016, 'Potensi Bioinsektisida Formulasi Cair Berbahan Aktif Beauveria bassiana (BALS.) VUILL dan Metarhizium sp. untuk Mengendalikan Wereng Coklat pada Tanaman Padi', Jurnal Sains dan Tenologi Tadulako, Vol. 5, no.3, hal. 25-30.

Kustiati, Yusmalinar S, Susanti S, Rahayu R, Heriani N, Ahmad I, 2016, 'Resistensi lalat rumah Musca domestica Linnaeus (Diptera: Muscidae) dari empat kota di Indonesia terhadap permetrin dan propoksur', Jurnal Entomologi Indonesia, Vol. 12, no. 3, hal. 123-124.

Lestari, Yuniar., Boewono, Damar T. dan Iravati, Susi, 2005, 'Efektivitas Ekstrak Etanol Beberapa Jenis Tanaman terhadap Mortalitas Lalat Musca domestica di laboratorium', Sains Kesehatan, Vol. 18, no. 1.

Nunilahwati H, Herlinda S, Irsan C, Pujiastuti Y, Khodijah \& Meidelima D, 2013, 'Uji Efikasi Bioinsektisida Jamur Entomopatogen
Berformulasi Cair terhadap Plutella xylostella (L.) di Laboraturium', J. HPT Tropika, vol. 13, no. 1, hal. 52-60.

Prasasya, 2008. Uji Efikasi Jamur Entomopatogen Beauveria bassiana balsano dan Metarrhizium anisopliae (Metch). Sorokin terhadap Mortalitas Larva Phragmatoecia castanae Hubner di Labolatorium, Skripsi, Departemen Ilmu Hama dan Penyakit Tumbuhan Fakultas Pertanian, Universitas Sumatera Utara, Medan.

Rosmini dan Lasmini S.A, 2010, 'Identifikasi Cendawan Entomopatogen Lokal dan Patogenitasnya terhadap Hama Wereng Hijau (Nephotettix virescens Distant.) Vektor Virus Tungro pada Tanaman Padi Sawah di Kabupaten Donggala', Jurnal Agroland, vol. 17, no. 3, hal. 205-212.

Samuels, R.I, Coracini, D.L.A., Dos Santos, C.A. Martins, Gava, C.A.T. 2002. 'Infection of Blissus antillus Eggs by the Entomopathogenic Fungi Metarhizium anisopliae and Beauveria bassiana'. Biological Control vol. 23, no. 3, hal. 269273.

Trizelia, Syahrawati, MY, dan Mardiah, A, 2011, 'Patogenitas Beberapa Isolat Cendawan Entomopatogen Metarhizium spp. terhadap Telur Spodoptera litura Fabricius (Lepidoptera: Noctuidae)', J. Entomol. Indon., vol. 8 , no. 1, hal. 45-54.

Trizelia, Nurbailes, dan Ernawati, D, 2013, 'Virulensi Beberapa Isolat Jamur Entomopatogen Metarhizium SPP. terhadap Hama Penggerek Buah Kakao Conopomorpha cramerella Snell. (Lepidoptera: Gracillariidae)', J.HPT Tropika, vol. 13, no. 2, hal. 151-158.

Widiyanti, Ni Luh P.M. dan Muyadihardja, S. 2004. Uji Toksisitas Metarhizium anisopliae terhadap Larva Nyamuk Aedes Aegypti. Media Litbang Kesehatan Volume XIV Nomor 3 Tahun 2004.

Yanti, I, 2013, Pengaruh Jamur Entomopatogen (Metarhizium anisopliae) terhadap Mortalitas Serangga Penyerbuk (Trigona sp.), Skripsi, Universitas Islam Negeri Sunan Gunung Djati, Bandung. 